\title{
Michael Beurskens
}

\section{Privatrechtliche Selbsthilfe}

Rechte, Pflichten und Verantwortlichkeit bei digitalen Zugangsbeschränkungs- und Selbstdurchsetzungsbefugnissen

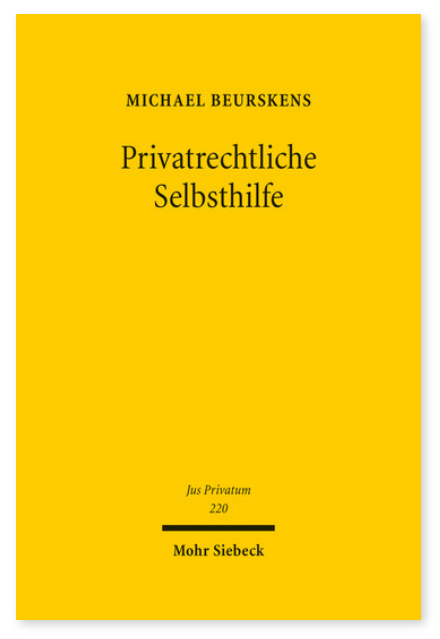

2017. XVI, 488 Seiten. JusPriv 220

ISBN 978-3-16-154426-2

DOI 10.1628/978-3-16-154426-2

eBook PDF 134,00€

ISBN 978-3-16-154425-5

Leinen $134,00 €$
Nach § 446 BGB geht mit der tatsächlichen Sachherrschaft die Gefahr der Verschlechterung oder des Untergangs der gekauften Sache auf den Käufer über. Was aber gilt, wenn der Verkäufer die Sache über Updates auch danach weiter verändern kann? Das Internet eröffnet neue Möglichkeiten, durch technische Mechanismen einen Zugriff auf oder eine Nutzung von Daten, aber auch vernetzter Geräte zu verhindern oder zu beschränken. Die Rechtsordnung gibt darauf bislang keine einheitliche Antwort.

Ausgehend von § 229 BGB über den Geheimnisschutz nach § 17 UWG bis hin zum Computerstrafrecht umfasst die Arbeit ein weites Feld von Eingriffsmöglichkeiten und entwickelt Grundsätze für die Handhabung der absehbaren Problemfälle. Dabei wird die wirtschaftliche Bedeutung anhand ökonomischer Methoden beurteilt und vergleichend das US-amerikanische Recht herangezogen.

Michael Beurskens Geboren 1977; Studium der Rechtswissenschaft in Düsseldorf; 2004 LL.M. (Gew.

Rechtsschutz/Düsseldorf); 2005 LL.M. (University of Chicago) und Attorney at Law (New York); 2007 Promotion; 2013 Habilitation; derzeit Professor für Bürgerliches Recht an der Rheinischen Friedrich-Wilhelms Universität Bonn.
Jetzt bestellen:

https://mohrsiebeck.com/buch/privatrechtliche-selbsthilfe-9783161544262?no_cache=1

order@mohrsiebeck.com

Telefon: +49 (0)7071-923-17

Telefax: $+49(0) 7071-51104$ 